MISES: Revista Interdisciplinar de Filosofia, Direito e Economia ISSN 2318-0811

Volume IV, Número 1 (Edição 7) Janeiro-Junho 2016: 283-293

\title{
O Pensamento Econômico de Monteiro Lobato
}

\author{
Márcio Bobik Braga* \\ Amaury Patrick Gremaud ${ }^{* *}$
}

\begin{abstract}
Resumo: Este artigo tem como objetivo interpretar o pensamento econômico de Monteiro Lobato. A partir da leitura de alguns dos seus livros para adultos, podemos perceber que Monteiro Lobato foi um pensador liberal ao defender o padrão ouro e a redução do papel do Estado na economia. Também foi a favor da industrialização, porém por meio das inovações tecnológicas e da educação, além da melhor exploração dos recursos naturais.
\end{abstract}

Palavras-Chave: Monteiro Lobato. Literatura e história econômica. Pensamento econômico no Brasil.

\section{The Economic Thought of Monteiro Lobato}

\begin{abstract}
This article seeks to interpret the economic thinking of Monteiro Lobato. From the reading of some of his books for adults, we can see that Monteiro Lobato was a liberal thinker who defended the gold standard and the reduction of the role of the state in the economy. He was also in favor of industrialization, but through technological innovations and education, in addition to better exploitation of natural resources.
\end{abstract}

Keywords: Monteiro Lobato. Literature and economic history. Brazilian economic thought.

Classificação JEL: A12, B11.

\footnotetext{
" Márcio Bobik Braga é professor Livre-docente do Departamento de Economia da Faculdade de Economia, Administração e Contabilidade da Universidade de São Paulo, campus de Ribeirão Preto - FEARP/USP e do Programa de Pós-Graduação em Integração da América Latina - PROLAM/USP.

E-mail: marbobik@usp.br
}

** Amaury Patrick Gremaud é professor Doutor do Departamento de Economia da Faculdade de Economia, Administração e Contabilidade da Universidade de São Paulo, campus de Ribeirão Preto - FEARP/USP e do Programa de Pós-Graduação em Integração da América Latina - PROLAM/USP.

E-mail: agremaud@usp.br

Os autores são gratos à Profa. Dra. Rosana Carmen de Meiroz Grillo Gonçalves, que nos incentivou a ler Lobato. 


\section{I - INTRODUÇÃo}

Nascido na cidade de Taubaté, em 1882, José Bento Monteiro Lobato (1882-1948) é um dos escritores mais conhecidos da literatura brasileira, principalmente pela coleção $\mathrm{OSi}$ tio do Picapau Amarelo, onde apresenta suas famosas histórias infantis e seus conhecidos personagens. Entretanto, o polêmico Lobato exerceu, ao longo de sua vida, várias outras atividades: foi pintor, fazendeiro, jornalista, bacharel em direito, empresário e editor de livros, tradutor, promotor público e adido comercial. Como escritor, não se limitou a escrever para o público infantil. Produziu também inúmeras obras para o público adulto nas quais escreveu sobre variados temas, dentre eles os coevos problemas econômicos do Brasil. O objetivo deste artigo consiste em identificar o pensamento econômico de Lobato a partir da leitura de algumas dessas obras.

A preocupação de Lobato com as questões econômicas do país ganha força com $M r$. Slang e o Brasil, publicado em livro em 1927, mas cujos textos apareceram originalmente em O Jornal no final de 1926 e início de $1927^{1}$. O livro é composto por diálogos entre um brasileiro anônimo e um inglês representado pelo personagem fictício Mr. Slang. É a partir da fala desse personagem que Lobato desenvolve suas ideias sobre economia². Esse diálogo é retomado no livro América, publicado originalmente em 1932, a partir da experiência do autor como adido comercial brasileiro em Nova Iorque, entre os anos de 1927 e 1931. Nestes dois livros, Lobato discute questões relacionadas com os problemas da estabilização da moeda no Brasil, o papel do governo na economia e algumas medidas que o país deveria adotar para diversificar sua produção, incluindo a industrialização. Em suas ideias,

\footnotetext{
${ }^{1}$ Estas datas, além da história do livro, consultar ABREU, Tâmara. Um xeque-mate nacionalista. In: LAJOLO, Marisa (org.). Monteiro Lobato livro a livro - obra adulta. São Paulo: Editora Unesp, 2014. p. 215.

${ }^{2}$ Sobre os personagens de Mr. Slang, ver ABREU. Um xeque-mate nacionalista, p. $223-224$.
}

Lobato se mostra um ortodoxo e um liberal convicto, hipótese que será defendida ao longo deste artigo.

A análise do pensamento econômico de Lobato foi realizada a partir da leitura de três dos seus livros para adultos: Mr. Slang e o Brasil, América e Prefácios e Entrevistas. Os dois primeiros se justificam pelos argumentos do parágrafo anterior. Já o livro Prefácios e Entrevistas constitui-se no último volume da primeira edição de suas obras completas, organizadas e publicadas pelo próprio autor no ano de 1946. Trata-se de um livro onde Lobato, já na maturidade, reúne um conjunto de entrevistas (além dos prefácios) realizadas durante a década de 1940, algumas das quais confirmam a análise econômica realizada pelo autor nos outros dois livros. Apesar desta pesquisa trabalhar com um número limitado de textos diante de uma extensa obra, partimos da hipótese de que os três livros aqui considerados representam o essencial do pensamento de Lobato, pelo menos nos temas aqui discutidos. Esta hipótese, porém, não descarta outras pesquisas sobre o pensamento do escritor ${ }^{3}$.

O essencial do pensamento econômico de Lobato foi concebido entre as décadas de 1920 e 1930 do século passado. Trata-se de um período de importantes mudanças no quadro econômico e político do país, com destaque para o conturbado período da Velha República. Entretanto, até mesmo pela limitação de espaço, o contexto histórico é apresentado em seus aspectos gerais, ficando para as notas de rodapé referências para estudos mais detalhados. Também não foi objetivo dialogar com os autores que escreveram sobre Lobato. Mesmo assim, são citados alguns dos seus principais biógrafos e críticos literários.

Deve-se destacar que Lobato escrevia para um público mais amplo da socieda-

\footnotetext{
${ }^{3}$ Deve-se destacar que, neste artigo, utilizamos edições contemporâneas dos livros de Lobato, ou seja, com as várias mudanças ocorridas na língua portuguesa. Este procedimento, entretanto, em nada muda a compreensão das citações.
} 
de. Logo, procurava utilizar exemplos do dia-a-dia para tornar mais didáticos seus argumentos. Entretanto, essa opção não diminui a importância das suas ideias sobre a economia brasileira.

O artigo está dividido em três seções, além desta introdução e das considerações finais. Cada seção representa um dos temas gerais identificados nas obras de Lobato aqui consideradas. A próxima seção trata da questão monetária desenvolvida pelo autor. A seguir, discutimos a participação do Estado na Economia. Finalmente, tratamos da estrutura produtiva concebida por Lobato e as formas de alcançá-la. Em suas propostas, o autor defende o liberalismo como a melhor opção.

\section{II - LOBATO E O PROBLEMA MONETÁRIO DO BRASIL}

Pode-se afirmar que o livro $\mathrm{Mr}$. Slang e o Brasil: colóquios com o inglês da Tijuca constitui-se na primeira tentativa de Lobato em sistematizar suas ideias econômicas ${ }^{4}$. Nele, Lobato apresenta seus argumentos de forma didática, propositalmente buscando substituir as informações prestadas pela imprensa que, segundo ele, eram distorcidas e não informavam à população a real condição econômica do país ${ }^{5}$.

A primeira questão econômica considerada por Lobato em $M r$. Slang refere-se à necessidade da manutenção do padrão ouro pelo Brasil. Nela, Lobato se mostra um convicto ortodoxo em termos monetários, defensor do padrão ouro que, no Brasil à época, denominava-se por metalista ${ }^{6}$. Já no início do

\footnotetext{
${ }^{4} \mathrm{O}$ termo "colóquios com o inglês da Tijuca" aparece da primeira edição do livro e não consta na edição aqui utilizada.
}

${ }^{5}$ LOBATO, Monteiro. Mr. Slang e o Brasil. São Paulo: Editora Globo, 2008, p. 25.

${ }^{6}$ No Brasil, os metalistas - defensores da estabilidade cambial e de um padrão monetário metálico - eram contrapostos pelos papelistas - que buscavam uma gestão monetária desvinculada da moeda metálica livro, considera que "para haver negócios, é preciso que o metro, o quilo e a moeda sejam constantes"7. Em seguida, afirma que "[a] medida do valor dos objetos chama-se ouro, como a medida da extensão é o metro e a medida do peso é o quilo"s. Sua preocupação estava focada na instabilidade do valor da moeda brasileira:

Réis é o nome em português do ouro-moeda. Esse mesmo ouro-moeda tem nos Estados Unidos o belo nome do dólar; na Inglaterra chama-se libra; na Alemanha, marco; na França, franco; na Itália, lira. Logo ... “100 mil-réis" quer dizer uma certa quantidade de ouro-moeda, e uma nota de 100 mil-réis quer dizer um vale, um título ao portador, sem prazo de resgate na importância de 100 mil-réis de ouro. E como ninguém desconfia do governo, esse vale circula como se fosse ouro. Quem quiser trocá-lo pelo metal correspondente é só ir ao Tesouro e apresentá-lo. Mas desde que o governo se acanalha

e adequada às necessidades de circulação da praça. O debate em torno da moeda e sua gestão foram intensas desde o Império e também durante a Primeira República, contexto em que Lobato escreve $M r$. Slang. Em parte o debate entre papelistas e metalistas se aproximava dos debates internacionais, sobretudo ingleses, acerca da política monetária e que envolviam os adeptos da Banking School, em oposição à Currency School. Esta última foi a corrente que prevaleceu representando a ortodoxia monetária defendida por David Ricardo e, no Brasil, se aproximava da visão metalista defendida por Lobato. Como representantes dos metalistas no Brasil podemos considerar nomes importantes como os Ministros da Fazenda Joaquim Murtinho (1848-1911) e Leopoldo de Bulhões (18561928). Já entre os papelistas, destacam-se o Barão Irineu Evangelista de Sousa, mais conhecido como o Visconde de Mauá (1831-1889), o professor Vieira Souto (18491922) e o ministro Rui Barbosa (1849-1923). Não é por acaso que Lobato chama Rui Barbosa, em Mr. Slang, de "anomalia (...), nada tendo em comum com o país" (LOBATO. Mr. Slang e o Brasil, p. 27). Sobre o debate entre metalistas e papelistas ver GREMAUD, Amaury P. Das Controvérsias Teóricas à Política Econômica: Pensamento Econômico e Economia Brasileira no Segundo Império e na Primeira República. Tese de Doutorado, Faculdade de Economia, Administração e Contabilidade. Universidade de São Paulo, 1997.

${ }^{7}$ LOBATO. Mr. Slang e o Brasil, p. 35.

${ }^{8}$ Idem. Ibidem. 
e se recusa a pagar os vales emitidos, eles passam à categoria de letras que o aceitante se recusa a resgatar. Se o fato se desse com um particular, o remédio seria simples: execução e penhora. Mas como o caloteiro é grosso, o portador do vale não tem outro remédio senão procurar desconto na praça. E surge o câmbio?.

Aqui, Lobato critica a inconversibilidade do mil-réis, isto é, a não garantia, por parte do governo, da conversibilidade em ouro dos papeis moeda por ele emitido. Na prática a troca só poderia ser feita no mercado e neste o mil-réis variava em relação ao quanto de ouro e ou de outras moedas elas poderiam ser trocadas, mas sempre abaixo de quanto oficialmente o mil-réis deveria valer. Ou seja, Lobato chama a atenção para o problema da emissão de papéis pelo governo sem o lastro em ouro. $\mathrm{O}$ autor também sugere e critica a relação entre o desequilíbrio nas finanças públicas e o processo de emissão monetária, ou seja, a utilização do poder de emissão para financiar desequilíbrios nas finanças governamentais ${ }^{10}$. Outro resultado é o surgimento do que Lobato chamou de câmbio e sua volatilidade, ou seja, o aparecimento da desvalorização cambial (desvalorização do mil-réis) e da instabilidade cambial, fonte da existência do risco cambial enfrentado pelos investidores externos:

Tive um amigo de Londres que num momento de cegueira aplicou aqui 10 mil libras a $9 \%$, dinheiro esse que na Inglaterra

\section{${ }^{9}$ LOBATO. Mr. Slang e o Brasil, p. 36.}

10 Essa é a grande crítica feita pelos metalistas aos papelistas. Para os metalistas, como o mil-réis deveria representar uma moeda com conteúdo metálico e este conteúdo seria dado pela taxa de troca (fixa) entre o mil reis e uma quantia de ouro. As emissões de mil reis deveriam se limitar à uma quantidade equivalente ao volume de ouro disponível no país. Os papelistas acreditavam que se deveria emitir de acordo com as necessidades de circulação do mercado. A moeda em si, para os papelistas, não precisaria possuir um conteúdo metálico; ela seria apenas uma função que permitiria ou facilitaria os fluxos de negócios. Para os metalistas, esta posição não implicaria em qualquer freio à emissão, que acabaria financiando os gastos públicos, causando a perda da confiança e do valor da moeda. nunca lhe redera mais de $3 \%$. A perspectiva de triplicar a renda seduziu-o. Trouxe o dinheiro, reduziu-o a papel e, como o câmbio estava a 12 e a libra valia 20 mil-réis, achou-se com 200 contos, os quais, a 9\%, passaram a render-lhe 18 contos por ano. Meu amigo ficou radiante, visto que na Inglaterra só tirava desse dinheiro 6 contos. Empregou-o sob hipoteca, cujo contrato se venceu uns 4 anos atrás, com o câmbio a 5 . O devedor pagou-lhe pontualmente os 200 contos, mas o meu amigo, ao convertê-los de novo em libras, só se viu com 4.200 libras, em vez das 10 mil que trouxera. Está claro que fez "cruz canhoto" no Brasil e foi empregar o resto do seu dinheiro no Uruguai, onde o valor da moeda nacional é constante ${ }^{11}$.

Para Lobato, uma das consequências da desvalorização da moeda nacional e da instabilidade cambial seria a escassez de capitais externos, tão necessários para o desenvolvimento do país:

O Brasil constitui uma reserva imensa de possibilidades, que se transformarão em riquezas no dia em que houver o capital necessário para movimentá-las. O capital foge do Brasil. Isso explica a expansão assombrosa dos Estados Unidos e da Argentina, em contraste com o marasmo brasileiro. Capital procura negócios, não casas de jogo - e o Brasil não passa de um Monte Carlo em ponto grande ${ }^{12}$.

Segundo Lobato, “O Brasil muda tanto de orientação que é preciso ver primeiro" ${ }^{13}$; e

\footnotetext{
${ }^{11}$ Idem. Ibidem, p. 45. Ou seja, a moeda brasileira valeria $58 \%$ a menos, o que resulta, após alguns cálculos, no valor de 4.200 .
}

${ }^{12}$ Idem. Ibidem, p. 44.

13 Idem. Ibidem, p. 45. A condução da política econômica, sobretudo a monetária e cambial, sofreu muitas inversões ao longo da Primeira República, indo de momentos influenciados pelos papelistas como o início da primeira década republicana, o período da Primeira Guerra Mundial e o lustro que a ela se seguiu, para outros com influência ortodoxa como os governos Campos Salles (1841-1913) e Rodrigues Alves (1848-1919). Tivemos também uma experiencia com o Padrão Ouro, durante a fase em que prevaleceu a 
essa instabilidade estaria não somente afetando o comportamento dos investidores, mas também reduzindo a necessária corrente migratória proveniente da Europa ${ }^{14}$.

$\mathrm{O}$ autor também considera à clássica relação entre a emissão monetária e a inflação. Essa relação é expressa em entrevista de 1945 ao $D i$ ário de São Paulo, como consta em Prefácios e Entrevistas:

Penso que estamos atingindo o apogeu da inflação, da maior inflação jamais ocorrida em nossa história; e que, portanto, teremos que aguardar o fenômeno reverso: a maior deflação ou a maior crise da nossa história. Por inflação [...] entendo [...] a inflação monetária, esse tremendo derrame de papel-moeda sem nenhuma garantia lastro e, pois, condenado a ir-se depreciando como o antigo marco alemão ${ }^{15}$.

No entanto, Lobato não se limitou em considerar as consequências econômicas do problema monetário. Seu conceito de estabilidade é ampliado para a esfera social. A estabilidade monetária, para Lobato em Mr. Slang, teria o papel de aliviar as tensões sociais.

Digo já, pois toda revolução tem como causa última o mal-estar econômico. País que prospera não faz revoluções (...). A base de tudo é a fixidez. Primeiro estabilize, depois faça o que quiser. Estabilize, e o problema financeiro se resolverá por si mesmo. Estabilize, e a revolução perderá a sua razão de ser ${ }^{16}$.

Aqui, o termo problema financeiro representa, para Lobato, o déficit público; e a solução para tal problema estaria na estabilidade monetária, já que, para o autor, essa estabilidade tra-

Caixa de Conversão (1906 - 1914). Sobre essa história, ver GREMAUD. Das Controvérsias Teóricas à Política Econômica: Pensamento Econômico e Economia Brasileira no Segundo Império e na Primeira República.

${ }^{14}$ LOBATO. Mr. Slang e o Brasil, p. 46.

15 LOBATO, Monteiro. Prefácios e Entrevistas. São Paulo: Editora Globo, 2009. p. 135.

${ }^{16}$ LOBATO. Mr. Slang e o Brasil, p. 41. ria forte restrição orçamentária para o governo ${ }^{17}$. Já o termo revolução representa as inquietudes sociais decorrentes dos problemas econômicos, tão comuns no Brasil daquela época. A questão monetária estaria então não somente relacionada com os problemas econômicos, mas também com os problemas sociais ou mesmo políticos. Neste último caso e ao tratar das finanças públicas, Lobato reage ao ambiente de corrupção que confiava ele existir no Brasil de sua época:

Papel-moeda não é moeda-papel, como procurador sem procuração não é procurador. Papel-moeda quer dizer uma ladroeira que certos governos inventaram pelo simples fato de não haver cadeia para os governos. É o "palco" dos vigaristas [...]. Que é uma nota do Tesouro? Um vale que o Tesouro emite, apenas. Ora, esse vale realmente valerá enquanto o emissor for honesto e cumprir a sua palavra, resgatando-o [em ouro] pelo valor nele estampado sempre que lho apresentarem. Do contrário, não passa de pirataria ${ }^{18}$.

Ou seja, além de ressaltar a relação entre o sistema monetário e o político, o autor apresenta uma visão negativa sobre a atuação do Estado na economia ${ }^{19}$. Estudaremos esse ponto a seguir.

17 A caracterização do problema financeiro do país como sendo o problema das finanças públicas está presente no capítulo 2 do livro Mr. Slang. Ver LOBATO. Mr. Slang e o Brasil, p. 31-32.

${ }^{18}$ Idem. Ibidem, p. 36.

${ }^{19}$ Interessante notar que este livro publicado em 1927 foi escrito entre o final de 1926 e o início de 1927 . Neste mesmo momento, no final de 1926, em 18 de dezembro, Washington Luiz(1869-1957) (com Getúlio Vargas (18821954) Ministro da Fazenda) cria a Caixa de Estabilização que justamente reintroduz no Brasil o Padrão Ouro. Este pode ser mais um dos motivos pelo qual Lobato via o governo Washington Luiz, encerrando a, por ele fortemente criticada, fase "ciclônica" da República e iniciando uma nova fase, "um retorno à moralidade e ao compromisso público dos governantes inspirado no exemplo moralizador do próprio Presidente" (MOTA, D. G. M. da. Mr. Slang e o Brasil: A Escrita de Monteiro Lobato como Possibilidade de Interpretação da História Republicana. Campo Grande. Revista Monções, Vol. 1, No. 1, 2014. p. 74). 


\section{III - O gOVERno, O PARAsitismo E O FISCO}

Conforme visto no final da seção anterior, em suas análises sobre a questão monetária no Brasil, Lobato coloca as ações do governo (e, de uma forma geral, do Estado) como principal fonte de instabilidade econômica ${ }^{20}$. Entretanto, sua crítica não se limita a questões relacionadas às finanças públicas. Demonstra de forma explícita seu pessimismo em relação ao setor público. Esse pessimismo se justifica por pelo menos dois problemas colocados por Lobato: a ineficiência do Estado, tanto sob o ponto de vista burocrático como produtivo, e os malefícios da estrutura tributária brasileira.

Em Mr. Slang, Lobato considera que:

Não há serviço público que não empregue cinco homens, pessimamente pagos, para fazer, malfeitissimamente, a tarefa que um só, bem pago, faria com contento. Essa é a fórmula da burocracia brasileira, da qual decorrem três males: prejuízos do serviço público, miséria do funcionalismo e roubo de atividade à produção privada ${ }^{21}$.

Lobato considera o serviço público como uma atividade de baixa produtividade. A explicação estaria nas contratações de funcionários públicos sem critérios técni$\cos$, atendendo principalmente aos interesses políticos: "não há finalidade nos nossos serviços públicos a não ser dar emprego ao maior número possível de parasitas" ${ }^{22}$. E a

\footnotetext{
${ }^{20}$ Aqui, Lobato refere-se à principalmente à política econômica da Primeira República, particularmente aquelas que marcaram a economia no pós-Primeira Guerra Mundial.Sobre a instabilidade macroeconômica nesse período ver FRITSCH, Winston. Apogeu e crise na Primeira República, 1900 - 1930. In: PAIVA ABREU, Marcelo de. A Ordem do progresso: dois séculos de política econômica no Brasil. Rio de Janeiro: Elsevier Editora Ltda., 2014.
}

${ }^{21}$ LOBATO. Mr. Slang e o Brasil, p. 80.

${ }^{22}$ Idem. Ibidem, p. 81. Aqui, a utilização do termo parasitismo representa não apenas o uso de uma palavra com sentido pejorativo, mas também a influência das ciências naturais sobre o pensamento de consequência desse parasitismo seria a corrupção:

Há ladrões em excesso na caixa-d'água do Tesouro deste país. O dinheiro se escoa em pura perda por milhões de canalículos insidiosos, com prejuízo da nação e das obras públicas $^{23}$.

Lobato apresenta, em Mr. Slang, vários exemplos para demonstrar a ineficiência do governo brasileiro. Um deles refere-se à Central do Brasil24:

Mas haverá neste país quem ignore que a Central ocupa o primeiro lugar entre todas as estradas do mundo em matéria de desastres? Que chegou à maravilha de num mês de não sei que ano conseguir o recorde de 32 desastres em trinta dias? Que a rubrica "Desastres da Central" se tornou permanente nos jornais? Que o povo traduz a E.F.C.B. como Estrada de Ferro Caveira de Burro? E porque é assim? Resposta: por que é federal, como muito bem explicou Dona Benta. Unicamente por isso. Existe em todos os serviços públicos federais um mal secreto que governo nenhum tem conseguido corrigir. Não há brasileiro que por experiência própria desconheça tal calamidade crônica, velhíssima, irredutível, agravada pela Republica Nova. O emperro burocrático, a falta de racionalização, a lentidão desesperadora do papelório, o descaso absoluto pelo público... Meu Deus! Haverá quem não tenha consciência da calamidade administrativa federal?

As estradas de ferro particulares, como a São Paulo Railway ou a Companhia Paulista, porque não são federais, mostram-se modelares. A São Paulo Railway só teve um desastre em toda sua existência - e isso ainda no tempo da Monarquia. Atravessou os quarenta anos da República Velha e os seis

Lobato. Provavelmente tirou esta expressão de Manoel Bonfim, que utiliza o termo para explicar os males da América Latina, inclusive do Estado. Sobre este ponto, ver PENTEADO, J. Roberto W. Os filhos de Lobato: o imaginário infantil na ideologia do adulto. São Paulo: Editora Globo, 2011. p. 71.

${ }^{23}$ LOBATO. Mr. Slang e o Brasil, p. 14.

${ }^{24}$ Idem. Ibidem, p. 80-81. 
da República Nova em um só acidente. O último desastre da Paulista foi há tanto tempo que dele o povo já não guarda memória. Por quê? Porque não são federais ${ }^{25}$.

Lobato também questiona a eficiência das forças armadas brasileiras, destacando o caso particular da Marinha ${ }^{26}$. Segundo Lobato, seria "tolice conservar máquinas atrasadas, de ineficiência evidente e reconhecida por todos os bons cérebros de que a Marinha dispõ $\mathrm{e}^{\prime 27}$. Para Lobato, era necessário modernizar as forças armadas e não utilizá-las para “justificar a extorsão de impostos e a manutenção de um bando imenso de parasitas, aqui e em quase toda parte" ${ }^{28}$.

Em América, apresenta outro problema gerado pelas ações do governo: suas intervenções no mercado do café brasileiro. Entende tais intervenções como criadoras de distorções que estariam afastando a economia de uma situação de maior eficiência:

A grande coisa é sempre esta: não fazer nada. Não interferir, não contrariar, deixar que o reajuste opere-se por si mesmo. Equilíbrio - ruptura de equilíbrio - reajuste: assim marcha o mundo. Não há um estalão supremo de verdade para verificar que forma de intervenção é a exata, de modo que não intervir dá sempre certo, porque não cria artificialmente em um erro novo ou a possibilidade dum erro. Veja no seu país [no texto, o Brasil] que desastre está sendo a interferência oficial no negócio do café. Houve um desequilíbrio entre a produção e o consumo. Em vez de deixarem que o natural reajuste se fizesse, surgiu a intervenção do Convênio de Taubaté - semente da maior calamidade que vai desabar sobre o Brasil ${ }^{29}$.

${ }^{25}$ LOBATO. Prefácios e Entrevistas, p. 197-198. Aqui, a referência à Dona Benta decorre do livro Geografia de Dona Benta, publicado originalmente em 1935.

${ }^{26}$ LOBATO. Mr. Slang e o Brasil, p. 137-138.

${ }^{27}$ Idem. Ibidem, p. 138.

${ }^{28}$ Idem. Ibidem, p. 97.

${ }^{29}$ LOBATO, Monteiro. América. São Paulo: Editora Globo, 2009. p. 83. O Convênio de Taubaté foi assinado em fevereiro de 1906 pelos governadores dos estados
Percebe-se na leitura desse texto a preocupação de Lobato em comparar o público com o privado; o intervencionismo com as livres forças de mercado; e nessa comparação, fica também evidente a opção de Lobato pelo liberalismo.

A intervenção do governo do mercado cafeeiro se fez ao longo de quase toda a Primeira República: em 1906 (em decorrência do referido Convênio de Taubaté), durante a Primeira Guerra Mundial, em 1921 e a partir de 1924 de forma permanente pelo Instituto de Defesa do Café de São Paulo. A intervenção se dava pela retirada de parte da oferta do mercado (estocagem) de modo a buscar sustentar os preços, os quais estavam em queda em função do descompasso entre a abundante oferta e a demanda. Em um momento posterior esperava-se uma quebra de safra para a desova dos estoques. A crítica era que se não houvesse eventos naturais (geadas) que reduzissem a oferta, esta tenderia a permanecer excessiva e os produtores de café continuariam a plantar o produto. No fundo, o sinal que o mercado enviava indicava um problema: a queda dos preços e o excesso de oferta estavam sendo escondidos pela intervenção pública. O problema seria ampliado a partir do continuo reinvestimento dos cafeicultores na própria atividade.

Ainda no caso das políticas de valorização do café, Lobato considerou outra distorção: a concentração das exportações brasileiras em poucos produtos. Sem mostrar dados, apresenta um gráfico de barras com o formato semelhante à letra "L":

[O] país está a equilibrar-se sobre a perna magra deste " $L$ ", representado na haste grande pela exportação do café e nos "cepinhos" de baixo pelas do cacau, couros,

de São Paulo, Jorge Tibiriçá (1855-1928), de Minas Gerais, Francisco Antônio de Sales (1863-1933), e do Rio de Janeiro, Nilo Peçanha (1867-1924). Estabelecia as bases de uma política conjunta de valorização do café, condicionado à aprovação pelo presidente da República. Entretanto, o presidente Rodrigues Alves se recusou a assinar o acordo, que foi ratificado, então, pelo seu sucessor, Afonso Pena (1847-1909). Ver FRITSCH. Apogeu e crise na Primeira República, 1900 $-1930$. 
mate, sementes oleaginosas e mais quireras que o Brasil vende para o exterior ${ }^{30}$.

De fato, durante a década de 1920 (e a situação estende-se até a década de 1960), o café foi de longe o principal produto da pauta de exportações brasileiras. O que incomodava Lobato era o fato dessa estrutura produtiva estar sendo conduzida não pelas forças de mercado, mas pelo intervencionismo irresponsável do governo. Isso sugere a possibilidade de outra estrutura produtiva. Este ponto será discutido na próxima seção.

Outro objeto de análise feita por Lobato refere-se à estrutura tributária do país. Este tema já aparece em Mr. Slang, mas é mais bem desenvolvido em América. Lobato considerava essa estrutura tributária ineficiente, mal distribuída e criadora de distorções no sistema produtivo do país. Tratava-se, segundo o autor, de uma herança do período colonial:

É mal que vem de trás, dos tempos do Brasil Colônia. Portugal, ao tomar posse da terra nova, cuidou de uma coisa só: o Fisco. A colônia existia para o Fisco. A Fazenda Real era tudo e os interesses do povo eram nada. E o Fisco se organizou atendendo unicamente às suas conveniências. A inépcia desta concepção é que nos permitiu, a nós ingleses, tomarmos conta de todas as colônias lusas que nos convinham [...]. Veio depois a independência, a Monarquia, a República, e em todas estas mudanças se mexeu em tudo, menos no Fisco. Ficou ele com o mesmo arcabouço e a mesma psicologia colonial. Daí a sua forma de castigo ao trabalho, de empeço aos movimentos livres, que caracterizam as taxas republicanas, culminadas agora no monstruoso imposto sobre a renda. E o país que se desiluda. Não haverá progresso possível enquanto não houver mudança de mentalidade a este respeito. Não é amarrando um homem e embaraçando-lhe todos os movimentos que esse homem ganhará corridas no steeple-chase internacional ${ }^{31}$.

\footnotetext{
${ }^{30}$ LOBATO. América, p. 84.

${ }^{31}$ LOBATO. Mr. Slang e o Brasil, p. 62.
}

Lobato destaca, em sua crítica, dois impostos que ele define como antieconômicos: o de importação e o de exportação ${ }^{32}$. Ou seja, a base da arrecadação brasileira e do financiamento público do período seriam os tributos que incidem sobre o comércio internacional. São tarifas aduaneiras em geral elevadas que obstruem o livre comércio do país com o resto do mundo. Este ponto é particularmente importante na discussão sobre o modelo econômico idealizado por Lobato para o Brasil.

\section{IV - O LiBERALISMO E A INDUSTRIALIZAÇÃO}

Pode-se considerar que, implícito nas ideias de Lobato, existe um projeto de industrialização para o Brasil. Em América, no capítulo que se inicia com a mais famosa de suas frases: um país se faz com homens e livros, Lobato exalta os Estados Unidos como "um país de alta civilização industrial" ${ }^{33}$. Estava impressionado com a emergente potência industrial. A industrialização concebida por Lobato, entretanto, difere das ideias de vários economistas que defenderam a industrialização substitutiva de importação no Brasil ${ }^{34}$. Para Lobato,

${ }^{32}$ Idem. Ibidem, p. 62.

33 LOBATO. América, p. 61. Entre a publicação do livro Mr. Slang e do livro América, Lobato viveu nos Estados Unidos como adido comercial. Neste sentido, é interessante notar que em $\mathrm{Mr}$. Slang, apesar de apresentar várias citações sobre os Estados Unidos, existem fortes referências aos aspectos civilizadores da Inglaterra. Já em América, as referências à Inglaterra diminuem enquanto que o modelo modernizante dos Estados Unidos se torna central. Ver: MEIHY, José Carlos S. B. Mr. Slang: um inglês na Tijuca ou de Cambridge a Cambridge. In: AGUIAR, Flávio \& VASCONCELOS, Sandra G. T. (Orgs.) Imagens da Europa na literatura brasileira. São Paulo: Humanitas/ FFLCH/USP, 2001. p. 21-34)

${ }^{34}$ Aqui, pode-se destacar aqueles ligados à Comissão Econômica para a América Latina e Caribe - CEPAL, como Celso Furtado, que sempre se mostrou contra a prevalência de ideias liberais no Brasil. Também observou a industrialização norte-americana, ocorrida com a adoção de medidas protecionistas, impostos sobre importações, como as defendidas por Alexander 
não havia contradição entre o liberalismo e a industrialização.

Conforme visto na seção anterior, para Lobato os impostos de importação estariam no conjunto de impostos antieconômicos. Teriam, como consequência, a criação de estruturas produtivas ineficientes. $\mathrm{O}$ autor reconhecia os positivos efeitos protecionistas da Primeira Guerra Mundial sobre as indústrias domésticas. Considerava, entretanto que, após o conflito, essas indústrias somente se sustentariam com altas taxas de importação protecionistas, o que seria um equívoco ${ }^{35}$. Para Lobato:

Só uma coisa cria a indústria, a boa, a sólida indústria que presta serviços à sociedade humana - e essa coisa é incompatível com o protecionismo (...)

A humanidade somente progride dentro do respeito às leis biológicas. A concorrência é a lei biológica do progresso. Tudo quanto impede, embaraça ou retarda a concorrência atua contra o progresso. O protecionismo impede a concorrência. Logo, é a morte da indústria ${ }^{36}$.

Mas como criar indústrias sem o protecionismo? Podemos encontrar, em seus textos, pelo menos cinco ações necessárias para a criação de condições para a existência de indústrias no país. As mais conhecidas são a defesa de uma indústria metalúrgica nacional e a exploração de petróleo no país, além do desenvolvimento de um sistema de transporte eficiente. As outras duas estão relacionadas com as inovações tecnológicas e com a qualificação da mão de obra. Vejamos como Lobato trata cada uma dessas ações.

Às vezes de forma exageradamente didática, Lobato considerava o ferro como matéria-prima essencial para a construção de máquinas, necessárias tanto para a mo-

Hamilton (1757-1804) nos Estados Unidos, fato de amplo conhecimento mas que não é destacado por Lobato.

${ }^{35}$ LOBATO. Mr. Slang e o Brasil, p. 70.

${ }^{36}$ Idem. Ibidem, p. 68. dernização agrícola como para a criação de um ambiente propício à criação de indústrias. Também considerava o petróleo como principal fonte de energia a ser explorado no Brasil. Esse discurso pode ser encontrado em América:

Do óxido de ferro o saudável homem daqui tira o aço. Com o aço cria a máquina, isto é, a astuciosa maneira de multiplicar tremendamente a força do músculo, ou substituí-lo no trabalho. Depois, por meio da hulha e do petróleo a energia mecânica com a qual move a máquina. Desse modo domina a natureza, mobiliza-lhes as reservas ocultas no seio da terra e transforma-se em utilidades - em riqueza ${ }^{37}$.

Lobato, aliás, seria conhecido como defensor da exploração de petróleo no Brasil, cuja abundância ele acreditava existir. A partir dessa defesa, foi e ainda é considerado por muitos como um autor nacionalista. Esta caracterização, entretanto, deve ser relativizada, pois Lobato era a favor dos capitais externos, da imigração e do livre comércio.

Com o país produzindo os recursos naturais necessários à criação de estruturas mais eficientes, estaria então em condições de investir na infraestrutura de transportes, não apenas como fator de integração:

[A] estrada é tudo em um país, mas absolutamente tudo! É a instrução, a riqueza, a defesa, a ordem, a lei, a polícia, o progresso, a felicidade (...). Há dias li no Today and tomorrow, do grande Henry Ford, um livro que está fazendo furor no mundo mas que vocês inocentemente ignoram, uma opinião sobre o Brasil. Diz ele: "For while Brazil takes up one fifteen of earth's surface and has extraordinarily rich natural resources, is has not had transport facilities for development. A country develops only according to the ease of transport, and most of Brazil has only six months of transport by motor because, during the other six months, the roads are too heavy for any car to force through". Vê? Ford tem a mentalidade dos povos estradeiros e, sem

${ }^{37}$ LOBATO. América, p. 95. 
nunca ter estado aqui, compreendeu o que pouquíssimos brasileiros compreendem ${ }^{38}$.

Nesta última citação e em outras partes do livro, percebemos a admiração que Lobato nutre pelo empresário estadunidense Herry Ford. Tal admiração parece ter surgido a partir da tradução que Lobato fez das obras do empresário e reforçado pela sua viagem aos Estados Unidos, onde visitou sua fábrica de automóveis. ${ }^{39}$ Lobato se vê fascinado com a liderança e com a eficiência conduzidas por Ford. Em Mr. Slang, Lobato destaca-o na história da empresa norte-americana Detroit-Toledo \& Ironton:

Conhece a história da Detroit-Toledo \& Ironton? (...) Pois vale por história muito ilustrativa. Nunca deu lucro, arrecadava 100 e gastava 150, servindo pessimamente ao público. Quebrou diversas vezes, foi organizada outras tantas e por fim tornou-se a armadilha financeira mais duvidosa da América. Chegou a cair em abandono. Estava nesse miserável estado quando Herry Ford a adquiriu ${ }^{40}$.

Para Lobato, a partir da intervenção de Ford, a empresa teria ser transformado em: um mimo de eficiência, asseio e ordem, trazendo satisfeitíssimos os que nela trabalham (...), o público, que jamais teve melhor transporte, e o dono, que aufere uma renda soberba. Antes da aplicação do método Ford, os

\footnotetext{
${ }^{38}$ LOBATO. Mr. Slang e o Brasil, p. 104.

39 Conforme destacado na introdução deste artigo, Lobato também foi tradutor. Traduziu mais de 80 obras, incluindo textos de Friedrich Wilhelm Nietzsche (1844-1900), Albert Einstein (1879-1955), Herbert George Wells (1866-1946) e Irmãos Grimm. No caso do empresário Henry Ford (1863-1947), traduziu os livros Minha Vida e Minha Obra e Hoje e Amanhã. Estas informações foram tiradas da biografia clássica realizada por Edgard Cavalheiro: CAVALHEIRO, Edgard. Monteiro Lobato: Vida e Obra. São Paulo: Companhia Editora Nacional, 1956. p. 293) que também pode ser encontrada em LAJOLO. Monteiro Lobato livro a livro - obra adulta. Sobre a visita de Lobato à Ford, ver MEIHY, José Carlos S. B. How Henry Ford is regarded in Brazil: a dimensão industrializante do pensamento lobatiano. In: LAJOLO. Monteiro Lobato livro a livro - obra adulta.

${ }^{40}$ LOBATO. Mr. Slang e o Brasil, p. 85 - 86.
}

empregados se queixavam, queixava-se o público e queixavam-se os acionistas ${ }^{41}$.

Em várias partes da sua obra, Lobato exalta as características positivas do empresário: a valorização do trabalho, a organização produtiva, o aumento da produtividade e a cobrança de resultados ${ }^{42}$. Foram essas estratégias que, segundo o autor, tornaram possível a recuperação da empresa, transformando-a "na mais rentável e perfeita estrada de ferro americana" ${ }^{\prime 3}$. Nesse sentido, o autor toma o método fordista de produção como referência de modelo a ser adotado pelas indústrias a serem implantadas no Brasil.

Além da trilogia "ferro, petróleo e transportes", Lobato considerou a importância da inovação e da qualificação da mão de obra como condições necessárias à criação de indústrias no país.

A importância que Lobato dá à inovação para o desenvolvimento econômico pode ser percebido em uma citação do livro América:

Cada vez que aparece alguma nova máquina, ou nova invenção - e progredir é isso, maquinar, inventar -, criam-se condições novas de vida, que provocam deslocações de homens. Quando apareceu o automóvel, milhares de cocheiros foram deslocados de suas boleias, milhares de tratadores, milhares de tratadores de cavalos foram para o olho da rua. Crise? Deslocamento apenas. A máquina nova não veio diminuir o trabalho, sim aumentá-lo, como os fatos o provam. Apenas criou trabalho novo. Surgiu a tarefa nova do chauffeur, e as dos reparadores de carros, lavadores, vendedores de gasolina e todo esse mundo da indústria automotiva. E aqui temos o ponto. Os cocheiros e mais homens postos à margem pelo auto foram em número tremendamente inferior ao dos homens chamados a desempenhar as tarefas novas que o automobilismo criou $^{44}$.

\footnotetext{
${ }^{41}$ Idem. Ibidem, p. 87.

${ }^{42}$ Idem. Ibidem, p. $86-87$.

${ }^{43}$ Idem. Ibidem, p. 86.

${ }^{44}$ LOBATO. América, p. 79.
} 
Interessante notar nesta citação a reestruturação produtiva considerada por Lobato: mesmo que alguns percam com a inovação, o efeito sobre o emprego da mão de obra é positivo. Trata-se de um processo semelhante à denominada destruição criativa, apresentado formalmente pela primeira vez por Joseph A. Schumpeter ${ }^{45}$.

Junto com a questão da inovação, Lobato considera a importância do capital humano para o desenvolvimento econômico. Isso fica explícito em América, onde Lobato se impressiona com a quantidade e qualidade das universidades estadunidenses:

O que a América está fazendo em matéria educativa excede o poder de previsão do cérebro humano. Meu problema é este: se a América em século e meio de vida independente fez o que estamos vendo, que fará num século ou dois mais a partir deste estágio de aparelhamento cultural de que se dotou? Inútil perder tempo com a questão. Nossos tataranetos, só eles poderão responder ${ }^{46}$.

Lobato retoma esta questão em Prefácio e Entrevistas:

A vitória da ciência no mundo moderno é absoluta; e o dilema, inexorável: ou um povo cultiva a ciência e vence ou permanece no empirismo dos avós e desaparece. E por que é assim? Porque só a ciência dá eficiência que tanto o indivíduo quanto os povos sobrevivem e vencem a competição. E que é eficiência? É fazer ponta num lápis com um canivete bem amolado, em vez duma faca de mesa sem cortes $^{47}$.

$45 \mathrm{Ou}$ seja, implícito na citação está o conceito de "destruição criativa", desenvolvido inicialmente por Joseph Schumpeter (1883-1950) em sua Teoria do Desenvolvimento Econômico (SCHUMPETER, Joseph A. Teoria do Desenvolvimento Econômico. São Paulo: Editora Abril Cultural, 1982) e aprimorado em suas obras posteriores, com destaque para o livro Capitalismo, socialismo e democracia (SCHUMPETER, Joseph A. Capitalismo, socialismo e democracia. Rio de Janeiro: Zahar Editores, 1984).

${ }^{46}$ LOBATO. América, p. 82.

${ }^{47}$ LOBATO. Prefácios e Entrevistas, p. 168.
Ou seja, em vez de criar indústrias, protegendo-as com altas taxas de importações e outras restrições, o país deveria criar condições internas favoráveis ao desenvolvimento espontâneo de uma estrutura produtiva eficiente.

\section{V - Considerações Finais}

Ainda que tenha influenciado vários projetos econômicos e sociais, o grande modelo concebido por Monteiro Lobato não se concretizou. O país sempre teve dificuldade em manter o Padrão Ouro. A inflação sempre foi um problema e a industrialização ocorreu com altas taxas protecionistas e com grande intervenção do governo nos negócios. Infelizmente Lobato, que veio a falecer em 1948 em São Paulo, não viveu o período do Pós-Guerra para defender suas ideias.

Deve-se destacar a atualidade das questões levantadas por Lobato: a importância da estabilidade monetária para o controle da inflação, os limites da atuação do Estado na economia e a necessidade de uma reforma tributária.

Lobato defendeu um projeto liberal para o país. A economia, segundo o autor, deveria ser conduzida por ações em direção à diversificação de sua estrutura produtiva, incluindo a industrialização, porém no contexto da estabilidade da moeda e com a livre atuação das forças de mercado. Pensou nesta reestruturação produtiva a partir da exploração dos recursos naturais e da criação de uma estrutura de transporte eficiente. Também considerou a importância das inovações tecnológicas, incluindo aí a qualificação da mão-de-obra. Ou seja, Lobato concebe um programa de desenvolvimento econômico liberal, com a mínima participação do Estado, algo muito diferente do que ocorreu no Brasil no Pós-Guerra. cos 